\title{
Música e Sociedade
}

\author{
Willy Correa de Oliveira
}

\section{Caro leitor,}

desde janeiro que, acusando o recebimento de cartas dos leitores, venho prometendo e protelando a publicação do nosso trabalho sobre a pedagogia musical. Mas novas cartas continuam a chegar. Acumulam-se novos pedidos. Me escuso por não havê-lo ainda dado o lume pelo fato de que o revestir. de letras a idéia, sempre estava a reclamar hora mais propícia, grave e minha própria contenção. E mesmo este trabalho que ora se publica na Revista Música Vol. $2 N^{\circ} 1$ eu o encontro muito tópico, sem dúvida, e a tal limite que não nutaria em intitulá-lo: "Breve resenha temática de minha pedagogia". Assim, longe de mim que eu nāo pretenda, tāo pronto, voltar a trabalhar, a desenvolver estes gregotins, mas a isto me remetcrei na medida em que os leitores, como de hábito, me escrevam - com a inclusão devida do cheque pagável em US\$ dólar ${ }^{\circ}$ - para o novo endereço: Rua Líbero Badaró, $\mathrm{N}^{\circ} 67,2^{\circ}$ andar, sala 2. CEP: 01008, São Paulo, Capital.

Sem mais, e agradecendo antecipadamente a atenção e as cartas dos leitores, despeço-me, deixando-os a sós com o texto que se segue.

Nosso projeto pedagógico se move a partir de um centro, do ponto focal da AFIRMAÇÃO DA PERSONALIDADE - e, para tanto, nos utilizamos do entrelaçamento paralelo das categorias prototípicas (que já é do conhecimento dos leitores, já partilha de seus universos míticos).

E para nós a PERSONALIDADE não pulsa em torno apenas da integralização de fatores psicológicos e morfofisiológicos. É um valor supremo a ser tratado como organismo em crescimento. Como uma planta tenra, cuja raiz é diversa do caule, das folhas, das flores, dos frutos e em plena diversidade anima-a um princípio unificador único. (Não se procura em uma árvore os frutos da outra. Não!) O caminho inelidível da descoberta do EU: somos co-partícipes desta caminhada: propiciamos sendas mais amenas, paisagens mais favoráveis. Nos propomos o papel de ladear os discípulos para, juntos, sentirmos as qualidades do sentimental: nos impressionamos com ele até o limiär da mais prenhe compassividade. Sinta-se, descubra-se, encontre-se. seja (:plenamente!) 
Os leitores que menos me conhecem (e ao meu MÉTODO), já devem estar algo impacientes ou desconcertados pelo fato de atingirmos tantas linhas sem a mais breve, ou passageira menção da palavra LIBERDADE. A liberdade, leitor, e o imo da afirmação da personalidade. É como a água para os peixes, como o ar que respiramos. Em nossa pedagogia começamos com os exercícios mais simples: na "sala branca" - de temperatura controlada - perfazemos com os participantes toda a série MARGE das práticas sobre o ILIMITADO; só após a água-de-coco comunal, é que nos retiramos. São os momentos fundamentais do nosso MÉTODO. Afirmamos, de fato, que a "sala branca" é o espaço singular onde o futuro artista se encontra admiravelmente com sua individualidade no ângulo da mais remível plenidāo. Para nós, $O$ individualismo é uma questão insubstituível; de tudo ou nada: apostamos todo o sonho no indivíduo, na personalidade, na mensagem do artista.

A liberdade, caro leitor, é como um trilho sobre o qual desliza a personalidade que se afirma na mais irreprimivel aventura de viagem. Mas quem somos nós, educadores, para decidirmos sobre trilhos, tractos, tráfegos e locomotivas? Antes tenhamos a sensibilidade (ver ainda a série MARGE das práticas sobre o ilimitado) de corretamente inferirmos qual paradigma-vaga é o mais contíguo ao indivíduo que temos diante de nós?

Relembrando os paradigmas-vagas, temos:

o INTROVAGANTE: aquele que encontra seu ponto-de-fuga no sonho. $O$ introspectivo, por excelência. Autor de delicadíssimos trabalhos em filigranas quase tonais. Ou próximos, como alguns miniaturistas do MINIMALISMO. o EXTROVAGANTE: aquele que extrata o insólito, o inaudito. É o homem nietzschiano em essência. É aquele que move as vanguardas. Como uma espécie de extrário, nós educadores, tenhamos cautela para não o turbarmos com inânias. É um "épateur" nato.

o AUTOVAGANTE: é o compositor de solilóquios de MUI longas durações. Vagam pelos sendeiros dos panoramas do próprio EGO. Daí que algo inatingível por nós; mas a nossa História da Arte tem mostrado que ele desfruta de lugar previlegiado em nosso arte-fazer. Devemos ser muito obsequentes - os arte-educadores - para com este artista-tipo. Ele pode - por exemplo - nos mimosear com uma obra para 4 seixos miúdos de cerca de 7 horas contínuas de duração para ser realizada em uma galeria de Arte de Nova Yorque.

Uma vez encontrado o paradigma-vaga que melhor entre em sintonia fina com a personalidade do nosso artista-a-vir-ser, não esqueçamos que é fundamental reforçarmos, sublinharmos em nossos discípulos aquilo que eles pensam que são (e não o que eles são efetivamente). É desta seiva que se nutre o jardim de nossas artes.

Passemos agora a tratar de um tema acogulado de melindres em nosso projeto. É que sem bases bem assentadas um edifício nâo reside duradouramente. Para que o nosso artista (ou mesmo fruidor de arte) se construa, é indispensável que se estruture com solidez aquilo que chamamos de os QUATRO PILOTIS do EGO. Esta ordem, serializada por mim desde 1971, já tem tido largo, e efetivo uso em trabalhos atuais de Schlowski e Härte. E, dado o 
conhecimento notório da questão, apenas, e para não deixar vão em nosso escrito, passo a nomé́-los de passagem:

O AUTORITARISMO: esta venerável coluna de sustentação não deve ser solapada impunemente. (Caro leitor, não é no pouco espaço que dispomos aqui, na revista, que iremos mostrar as infindáveis discussões que têm colmado este aspecto do sistema. Apenas, leitor amigo, apelo para o seu bom senso ao fazer patente que, em uma sociedade autoritária como a nossa (apesar das nuanças e sutilezas), o problema continua mascarado, mas não resolvido. O/A Sr./Sra. não permitiria que o seu autoritarismo fosse substituído pelo meu, por exemplo, não é assim?) Imagine então a propriedade do AUTORITARISMO de um artista! AUTOR / AUTORIDADE / AUTORITARISMO. Sem o autoritarismo - em essência - a imanizar a nossa ARTE, como seria possível vislumbrar a sua presença em nossa modernidade? Você sabe, leitor/a, de que estou falando. Mas, seja como for, acredito já haver dado o tiro de misericórdia sobre esta estúrdia discussão, no Congresso Mundial pela Arte, em Mitão, em novembro de 1987 . E para concluir este tópico:

A repressão sexual não pode ser excluída pura e simplesmente da nossa sociedade atual. E bem conhecemos a que grau de contiguidade se conformam autoritarismo e repressão sexual. $E$ ainda a que limites precisos se agrupam 0 autoritarismo, a repressão sexual e o poder social. A liberação sexual não ocorre porque você, ou eu, ou alguém apenas menciona a questão, não é assim? $E$ assim, para que continuemos civilizados, modernos, sejamos somente mais argutos, mais hábeis, mais delicados no sentido de objetivar uma repressão sexual mais eficiente para os dias atuais. Mas lembremos que, sem repressão, o autoritarismo pode ruir. $E$ não seria a ruína de nossa classe e, consequentemente, de nosso poder? Pense! Portanto, esta é uma questão - delicada, sim - mas que, embora engolfe a própria medula da nossa arte, a ultrapassa porque o dentro e o fora não se dão UNIpresentemente.

A OBEDIÊNCIA: só aprende a amar, a dar ordens, quem aprendeu a obedecer. A relação mestre/discípulo não deveria se estabelecer na anarquia. A inequívoca voz de comando s 6 vibra plenamente as cordas que se fortificam no repetir inefável dos sons quase inaudiveis (da obediência no tronitoar da voz de comando. A verdade de nossa arte. E você abriria mão, enquanto classe - pelo menos - de sua voz de comando? As relações com as orquestras sinfônicas, a arquitetura, um quadro pintado de branco, uma INSTALAÇ. $\vec{A}$, uma melodia que se repete de boca em boca desde as mídias, e quantos todos outros exemplos de nossa arte nào clamam a verdade da OBEDIÊNCIA? Pense! O tempo de aprendizado do artista é como uma caixa acústica para as cordas da obediência.

Fortalecer em cada EGO, ao máximo, os elementos fundamentais para seu pleno desenvolvimento. E, dando prossecução a este "vol d'oiseau" por sobre os Quatro Pilotis do EGO:

A ORDEM: se estabelece sobre a necessidade suprema de regras externas, bem definidas. Regras que, como a arte - de modo geral - possam substituir a realidade, de resto, matéria tão incômoda, convenhamos. Nosso traba- 
Tho maior deve ser dirigido no sentido de desenvolver a exteroceptividade do discípulo. Mas pequenos exercícios (como os que constam da série MARGE II, do livro rosa) devem ser desenvolvidos com os alunos: tanto em salas de aulas clássicas, quanto em práticas peripatéticas. O que é importante é que as regras tenham uma tal malha de relações internas que cheguem a mascarar a realidade eclipsada. Regras em lugar da realidade equivalem-se à ORDEM. Certamente que alguns discípulos são refratários à ORDEM... Estamos de acordo que existem, mas aí entra a capacidade do mestre (coadjuvado pelo ADENDA III da série MARGE II) no sentido de fortalescer, no aluno, a convicção de que ele PODE substituir regras externas por outras regras externas, confeccionadas por ele próprio. Mas cuide-se sempre para que regras externas tenham malhas de relações internas bem estruturadas.

E agora, quando chegamos à última coluna dos Quatro Pilotis do Ego, podemos entender claramente que estes pilotis (pedagógicos) têm uma sua especificidade: pois o AUTORITARISMO, a OBEDIÊNCIA e a ORDEM, juntos, fornecem a argamassa e os ferros para a fabricação da última das colunas de EGO:

A SEGURANÇA: esta necessidade do homem já se faz nele desde a lactação. E, diferentemente do alimento material, o composto alimentício espiritual básico para a nossa sociedade (expresso pelo pilotis do EGO) atinge seu zênite na necessidade de SEGURANÇA - que gera, por seu turno, o medo à liberdade. Eis o problema terminante para o Educador...

(Ora, se a liberdade - pensa o caro leitor - é aquilo que chamamos logo no início deste escrito, de trilho para a viagem fantástica e aventurosa da $A R$ TE, não chegamos aqui a um ponto de limite: ao limiar de uma devastação? Não se trata, pois, de uma aporia?)

Não. Não, se agirmos comprudência e seguirmos confidentemente o Adendum I da série MARGE II. Além dos exercícios proporcionais propostos, estão as colocações mais recentes de Schlowski \& Härte devidamente comentadas. Mas, en passant, eu gostaria de assentar aqui que a resolução do problema (crucial, assim também entendemos nós) está no trasladar do vórtice de significados da palavra LIBERDADE. Dar uma volta quase completa (mas de viés) no epicentro do vértice da relação SEGURANÇA-LIBERDADE. Eis em miúdos a questão trocada.

Está, pois, na ARTE o terreno privilegiado para a germinação da LIBERDADE. Na arte e em tudo que faz corpo com ela (desde os devaneios, nos sonhos, até no pesadelo). O fundamental está em não se plantar a liberdade no solo da realidade. Solucionamos dois problemas correlatos, afins: criamos, através da Arte, uma válvula de escape e deixamos intacta e ainda incólume, a REALIDADE.

Vejam bem, caros leitores, ao mesmo tempo em que mantemos quase que inabalável o nosso sentimento inquestionável de SEGURANÇA, criamos um espaço para o conflitual. desejo de liberdade - agora confinado na mitopoética da ARTE, enquanto defendemos por mais tempo o plano da REALI- 
DADE... Não é por muito menos que o artista já foi por Ezra Pound pensado como a ANTENA da RAÇA! A mitoplasticidade. Afinal, ao se aventurar o problema do homem (onde obviamente se insere o artista), perguntamos: é o homem um homem ou um arganaz?

Sei que muitos ainda se sentem incômodos devido à franqueza com que tratamos algumas peças importantes de nosso tabuleiro de Tabus. Mas estamos de acordo em que outros são os tempos atuais: agora tudo está muito mais claro. Muito mais claro inclusive com respeito a certas fragilidades de nosso sistema como um todo, e em particular com relação a seus pontos quebradiços, e a alguns escombros já havidos. Rebocos a olhos nus e sem tempo e materiais adequados para os trompe l'oeil dos tempos de juventude. Não se pode voltar atrás. E neste correr do tempo, apenas apresento um projeto pedagógico mais realista, em que nominamos com mais lhaneza: em que não induzimos ao erro de tratarmos o rei, a rainha, o bispo como peōes. Já fomos longe demais, Tabus, xadrez, grades, tabuleiros, peças brancas, pretas, as que saltam e as que as regras não permitem saltar. Seríamos os mesmos campeões em outro jogo? Catatraz!

Agora, passemos ao segundo movimento de nosso projeto pedagógico. Se o primeiro movimento tem um caráter épico, o segundo - vocês hão de concordar - é muito mais lírico, rapsódico. Com este movimento eu dotei o método de uma relação mais personalizada. Creio que vocês sentiram falta de algo neste sentido. Mas a questão é que não podemos pretender a uma ação pedagógica séria, moderna, unicamente com subsídios para o desenvilvimento de uma gestualidade apenas inter-pessoal. Bem sabemos que as relações singulares estão amparadas por algo mais difuso, mais geral, até mesmo de ordem inconsciente, mas tão concreto quanto os QUATRO PILOTIS DO EGO, tema principal de nosso primeiro movimento.

Agora estamos diante de um aluno, de um e um só e tão diferente e original e criativo quanto você que está lendo estas páginas.

$\mathrm{O}$ arte educador tem que estar atento, e com o espírito císsil para fazer face ao seu discípulo como um ser único, uno e tão insubstituível quanto qualquer um de nós (não é?), caro leitor/a, educađor/a, discípulo/a. Assim, não devemos jamais moldá-los à nossa imagem e semelhança: a cada um segundo suas tendências naturais. Para que lado sopram seus ventos, de que lado de suas paisagens nasce o sol? Não se aventurar a qualquer tipo de cultura sem o exame prévio das potencialidades do solo. E hoje já temos um razoável arsenal científico para a leitura dos terrenos; e sem os preconceitos do passado. Isto vale dizer que atingimos um instante em nossa cultura em que valorizamos os mais (aparentemente) antagônicos produtos estéticos. Já não choramingamos como o pobre Webern: "Viver é defender uma forma". Hoje os gêneros já não causam desavenças. Decisivo é o ato de fazer: gosto já não se discu- 
te, mesmo. Continuar fazendo é o desafio.

Meu método tem a vantagem de possibilitar diagnósticos-pedagógicos para as quatro vocaçóes básicas de nosso tempo:
A VANGUARDA - em suas trê vocatipyas
O Nacionalismo
A Arte Revolucionária
O Pós-TUDIsmo

que passamos a apresentar:

A vanguarda carrega em seu próprio bojo - e a despeito de suas vocatipyas e ênclises subsidiárias - uma índole para a substituição da realidade por uma atitude. Valiosa e indispensável é a premência neste campo da atividade humana da virtude da criatividade. Isto posto em momento ímpar de nossa evolução em que já somos criativos até ao atravessarmos as ruas.

VANGUARDA ESTRUTURALISTA: a atitude a substituir a realidade no caso que presentemente nos ocupa, resulta quase sempre da área conflitual que se situa na obliquidade do atrito provocado pela dissenção entre a visão de mundo proclamada nas histórias da arte - a zona de tornejamento do artista - e o mundo, a realidade tal qual se apresenta (quase insuportável) para o artista. É aí que se dá a grande projeção. Artistas vocacionados para este espaço têm necessidade de apoios científicos, lógicos para o pleno desabrochar de suas atividades. Devem ser oferecidas matérias de arrimo para sua parábase, como matemática elementar, os livros de iniciações científicas, pequenos manuais de lógica.

É muito comum neste artista a irritação proveniente da falta de capacidade do público (e até mesmo de seus pares) de compreender, por exemplo, que o 5o. compasso das Estruturas para 3 flautins decorre diretamente do retrógado da inversâo variada do motivo axial a ser introduzido no $31^{\circ}$ compasso. Por volta dos idos sessenta, essa música apresentava informações bastante pontilhísticas (ou pontuais, como escrevem outros estudiosos).

VANGUARDA SEMÂNTICA: aqui o que baila não é a lógica das estruturas, é a significação das entidades projetadas na obra. A originalidade atinge o fórum de ostentação. Originalidade e semântica se entrelaçam, se entretecem e se entreliçam em uma tarantela infernal no hecatônstilo de Falanto (segundo uma das lendas da guerra de Mesenya).

A ópera de Farley Greenhil ainda continua o marco desta estética. O compositor, seguindo estritamente sua partitura (em cuja notação figuravam manchas, pontos, elipses e textos em sânscrito), engole um microfone de contato e sobe a escada (único elemento cenográfico da ópera) e de lá enforca-se empurrando com os pés a escada que se precipita. O público, estarrecido, escuta a queda da escada $\mathrm{em}$ contraponto com os sons que eram difundidos pelos autofalante.

Diante de artistas da vanguarda semântica, o arte-educador deve funcionar desinflado de qualquer teoria e limitar-se a desimpedir o terreno por onde o artista quer se perder, vagar, encontrar o seu estro. Trata-se quase sempre de um abandônico típico. 
VANGUARDA POPULISTA: a designação desta vocatipya ocorreu independentemente de minha vontade, e de uso tão largo é, que apenas a emprego parcimoniosamente. A qualidade de sua ontogonia calca-se sobre o fato de o artista desistir de si próprio em favor da manifestação da música que público irá produzir. Geralmente enraiza-se em uma pulsão judaico-cristã a testemunhar em prol da auto-devoção do artista. Um cuidado especial deve ser tomado por parte do educador no sentido de se dispor continuamente a lembrar e a açular o seu discípulo com lisonjas que acariciem o seu ego brandamente. São, via de regra, os egos mais desenvolvidos que já tive conhecimento. Mais informações sobre o modo de tratar estas vocações são encontradas no Livro Marrom do Mestre da série MARGE DE PRÁTICA SOBRE O ILIMITADO, ediçāo de 1983.

Muitas vezes os compositores de música de VANGUARDA POPULISTA elaboram partituras complicadíssimas, chegando mesmo a requisitar vários regentes. Mas, em média, o público produz música com o que dispõe na platéia: suas gargantas, palmas, percussōes pedestres, cadeiras, programas e até mesmo suas boisas. Raras vezes sâe requisitados apitos, matracas, pequenos tambores, cornetas de brinquedo. Em produções mais apoiadas são distribuídos gratuitamente os objetos instrumentais com que o público - com seus improvisos - gratifica o seu compositor de vanguarda.

O NACIONALISMO: escola que se arrasta em nosso meio desde o final do século passado, caudatária das aquisições do século XIX, tem como força-de-expressão o verdeamarelazular tudo com entrelinhas brancas e faixa e ritmo bem brasileiros. Hoje estamos de braços abertos para recebermos esse modo de expressão estético. E a novidade está em que somos mais ecléticos e menos dogmáticos. E que acreditamos que a nossa cultura é muito rica e diversificada e com uns raios de sol tropical para todos os fins, e mais a nova consciência de que o tempo urge (e assim sendo), năo há como năo ter que ser resgatada esta corrente, não acham?

Em nossa pedagogia damos ênfase especial ao turismo, para o trabalho in loco sobre o que resta de folk music intocada pela revolução de 1964 e que estejam em fase de dispersão final a partir do alcance certeiro de nossa mídia televisiva. Nossos alunos se preparam para esta estética a partir de viagens de pesquisa de campo, com o auxílio de jovens guias turísticos, e mestres (devidamente cadastrados) de geografia, sociologia da Escola de Apipucos, luthiers c cenografos e figurinistas. Acreditamos firmemente no produto final de nosso trabalho ao podermos finalmente apresentar criadores capacitados a transformarem um Samba em Sinfonia, um Xaxado em um movimento de dança de uma SUITE SERTANEJA, assim como um Cateretê pode constituir um movimento de dança de uma SUITE CAIPIRA. Outros países do velho mundo já estão atentos para o trabalho que estamos desenvolvendo nesta área cultural! Queremos ressaltar - para dirimir possíveis dúvidas - que o nosso patriotismo é moderno, anti-inflacioário.

A ARTE REVOLLICIONÁRIA: O sistema tem, para sobreviver robustamente, necessidades de válvulas de escape para o acúmulo de tanto calor. $\mathrm{E}$ 
é neste sentido que, democraticamente, a nossa pedagogia acolhe artistas com tendências contrárias aos interesses de nosso modo de produção. Importam, basicamente, duas questões: por um lado, que o nósso compositor seja um REVOLUCIONÁRIO PADRÃO, e por outro, que suas produções sejam veiculadas para o nosso público e debaixo de nossos olhos, isto é, em nossas próprias salas. Têm garantido o nosso aplauso.

Vocês ainda devem estar lembrados do Lied de Manoel Francisco da Silva, no qual os enormes saltos vocais no campo de tessitura, e mais as pausas (necessidades de ordem estrutural, quase matemática) somadas às densidades variáveis dos blocos sonoros da orquestra, praticamente tornaram incompreensíveis as palavras do texto: "trabalhadores de todo mundo UNI-VOS". E, de mais a mais, você também sabe leitor/a, (não é certo?), que o público (parco até...) é antídoto eficaz. E não teria por que causar temores, nem mesmo que a letra fosse mais compreensível e revestida de roupagem neo-rococó.

O trabalho a ser desenvolvido com estes artistas já se encontra amplamente codjuvado pela MEDIA, pelos nossos desvelos (vejam as instruções à página 176 do Livro Marrom do Mestre) e vida afora pelo SISTEMA (produções eventuais de concertos, discos, vídeo) que os mantêm democraticamente ativos, mas inócuos. Quando é o caso, bem entendido.

O PÓS-TUDISMO: Com respeito a esta área do discurso cultural, peço vênia aos distintos leitores para silenciar. Muito por enquanto, talvez só por este escrito. Uma razäo provável é a de que me preparo atualmente para escrever um ensaio sobre esta via estética. Para isto, já estou de passagem comprada para a Itália, onde me instalarei na vila Asti (obra atribuída a Palladio) situada nos arredores de Verona, frente para o boschetto dei Pini Sacri. Antes pensava em me alojar em Castilloncello, para onde Byron partiu para escrever seu poema-tese "Birds of tyranies". Fica aqui a promessa de um "grande intreccio", que deve ser publicado em outubro. Uma segunda razão plausível é a de que as produções do pós-tudismo ainda se cumprem, ainda não se tornaram pós (completamente).

Aqui está, pois, em linhas mestras, os durâmenes de meu método pedagógico. Aos leitores, o meu convite para que aportem para a prática as cotas de suas criatividades sem as quais este trabalho pode se esvair em transpirações anódinas, sem mais.

Ainda umas poucas palavras antes da conclusão. Muitas tem sido as críticas desferidas contra o meu Sistema. Não para defender-me, por que acredito na antropossofia imanente ao Weltanschaung interposto no interstício da práxis com a teoria - mas mais para desfrangir receios ainda incertos nos seios de alguns leitores, é que retomo o problema do público.

Salvo raríssimas exceções que reforçam a regra, o público se torna cada vez mais ausente das salas de concerto. Os poucos que ainda persistem em tais frequentações já se dão conta do estado de suas solidões. Este aspecto tem sido apontado em detrimento do meu método, por insistir em propostas-dizem-desconsideradas pela economia de mercado. Exatamente o oposto, me permitam afirmar. Constato, dia a dia (e creio que o mesmo ocorre com 
vocês, leitores, amigos), que a nossa criatividade contactou o mais remoto linde em pleno século $X X$, quando somos criativos até ao levantarmos as mãos. E é neste oceano de criatividade que ouso (com o meu Sistema) a abordagem da questão por outro ângulo. $O$ que a nossa cultura vem logrando é a transubstanciação do público (do consumidor em produtor). É neste sentido que nos apoiamos na economia de mercado quando postulamos um método pedagógico que pretende alcançar não só alguns gênios em seus périplos de formação, mas sim a prestação de serviços a todo cidadão - um criador em potencial! Necessitamos a extinção de teatros e salas de concertos e suas substituições por novos e modernos edifícios que alojem salas para produções artísticas em que a existência de multi-palcos guarnecidos de espelhos ocupem o lugar que era desusadamente utilizado para a platéia. O meu Método tem hoje mais importância do que qualquer pedagogia anterior que apenas visava a possibilidade de dois, três gênios que porventura pudessem nos inquietar. Hoje, e é neste sentido que disponho a minha pedagogia, vejo em cada cidadão o seu próprio inquietador. No presente estamos investindo na industrialização de caixas contendo materiais, instrumentos e instruções para criações-em-séries à maneira dos "MAKE IT YOUSELF", e logo chegarão às prateleiras de supermercados, drogarias e bancas de revistas.

É preciso acreditar na economia de mercado!

"Tu le connais, lecteur, se monstre délicat,

- Hypocratique lecteur - mon semblable - mon frère!"

Au revoir!

Bouvril - páscoa de 1991

Nota

* De acordo com a tabela, ainda vigente, de 27 de abril, na conversão em cruzeiro na data da remessa. 